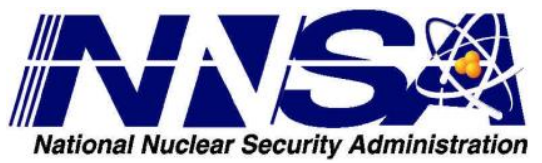

\title{
Module 4
}

\section{Threat Characterization}




\section{Threat Characterization}

- Design Basis Threat

- Defines the threat MPC\&A systems must perform against

- Based on threat assessment

- Periodically reviewed and revised 


\section{Threat Characterization}

(continued)

- Threat definition

- Types of adversaries

- Insiders

- Outsiders

- Insider/Outsider collusion

- Range of adversary tactics

- Capabilities

- Motivation 


\section{Insiders}

- Definition: Any individual with authorized access to nuclear facilities or transport who might attempt unauthorized removal or sabotage, or who could aid outsiders to do so.

- Insiders might include:

- Management

- Operations personnel

- Security personnel

- Service providers

- Visitors

- Inspectors

- Past employees

- Others? 


\section{Insiders}

(continued)

- Insiders represent formidable threats:

- they can often circumvent system elements

- they interact directly with the target without being detected

- The delay and detection timelines are not as relevant because insiders can choose the most opportune times and optimum strategies

- Insiders can roll-up materials to acquire a goal quantity 


\section{Insiders}

(continued)

\section{Categories:}

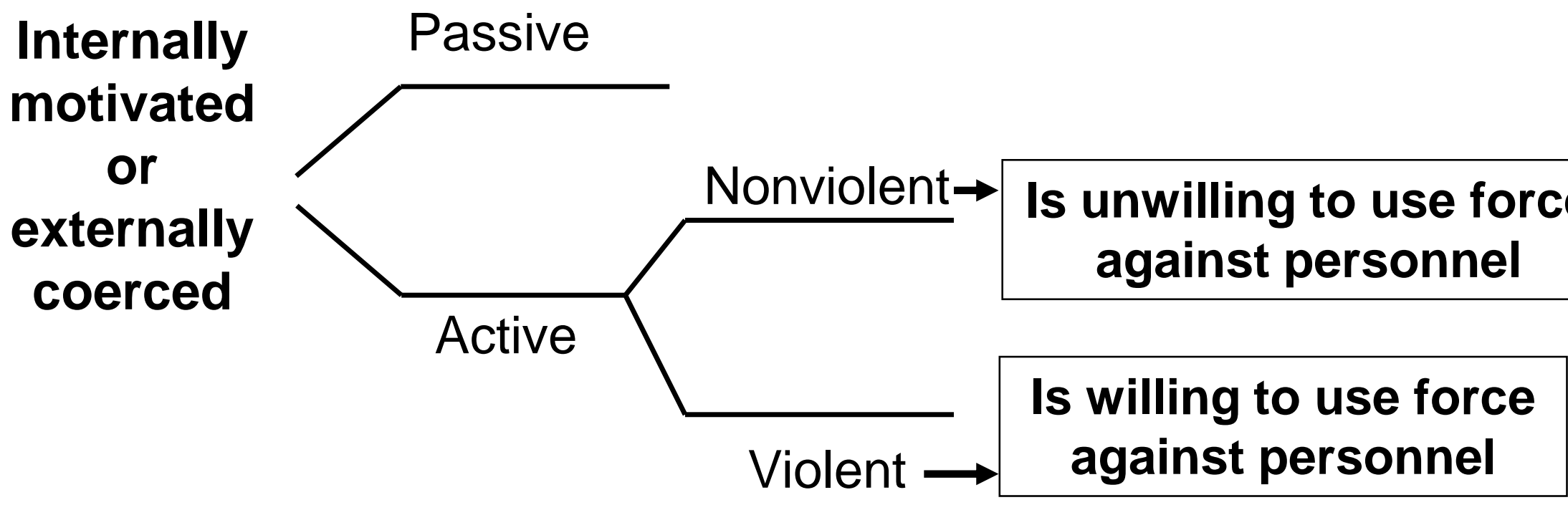

- All insiders can use stealth and deceit

- Violent insiders may be rational or irrational 


\section{Insiders}

(continued)

Motivations:

- Ideological - fanatical conviction

- Financial - wants / needs money

- Revenge - disgruntled employee or customer

- Ego - "look what I am smart enough to do"

- Psychotic - mentally unstable but capable

- Coercion - family or self threatened

Motivation is an important indicator for both level of malevolence and likelihood of attempt 


\section{Insiders}

(continued)

Advantages:

- Time

- Can select optimum time to implement plan

- Can extend acts over long periods of time

- Tools

- Has capability to use tools and equipment at work location

- Can attempt to introduce new tools as necessary

- Tests

- Can test the system with normal "mistakes"

- Collusion

- May recruit / collude with others, either insiders or outsiders 


\section{Insiders}

(continued)

\section{Access:}

- Authorized work areas

- Special temporary access

- Escorted or unescorted

- Restrictions on insider during access

- Emergency access (fire, medical, police, etc.)

- Unauthorized access

- Duration of target exposure

- Conditions of target during insider access

- Special site equipment

- Accounting database 


\section{Insiders}

(continued)

Knowledge:

- Targets

- Locations, characteristics, and details of targets

- Details of facility layout

- Security systems

- Security forces capabilities and communications

- Details of facility and security operations

- Location and details of safety and security protection systems

- Operations and processes

- Materials accounting

- Operational processes

- Tools and equipment 


\section{Insiders}

(continued)

\section{Authority:}

- Authority over people

- Designated authority over others

- Personal influence over others

- Authority over tasks and equipment

- Assessment of alarms

- Preparation of sensitive forms

- Authorization of processes and procedures

- Temporary authority

- Falsified authority

- Exemption from procedures 


\section{Insiders}

(continued)

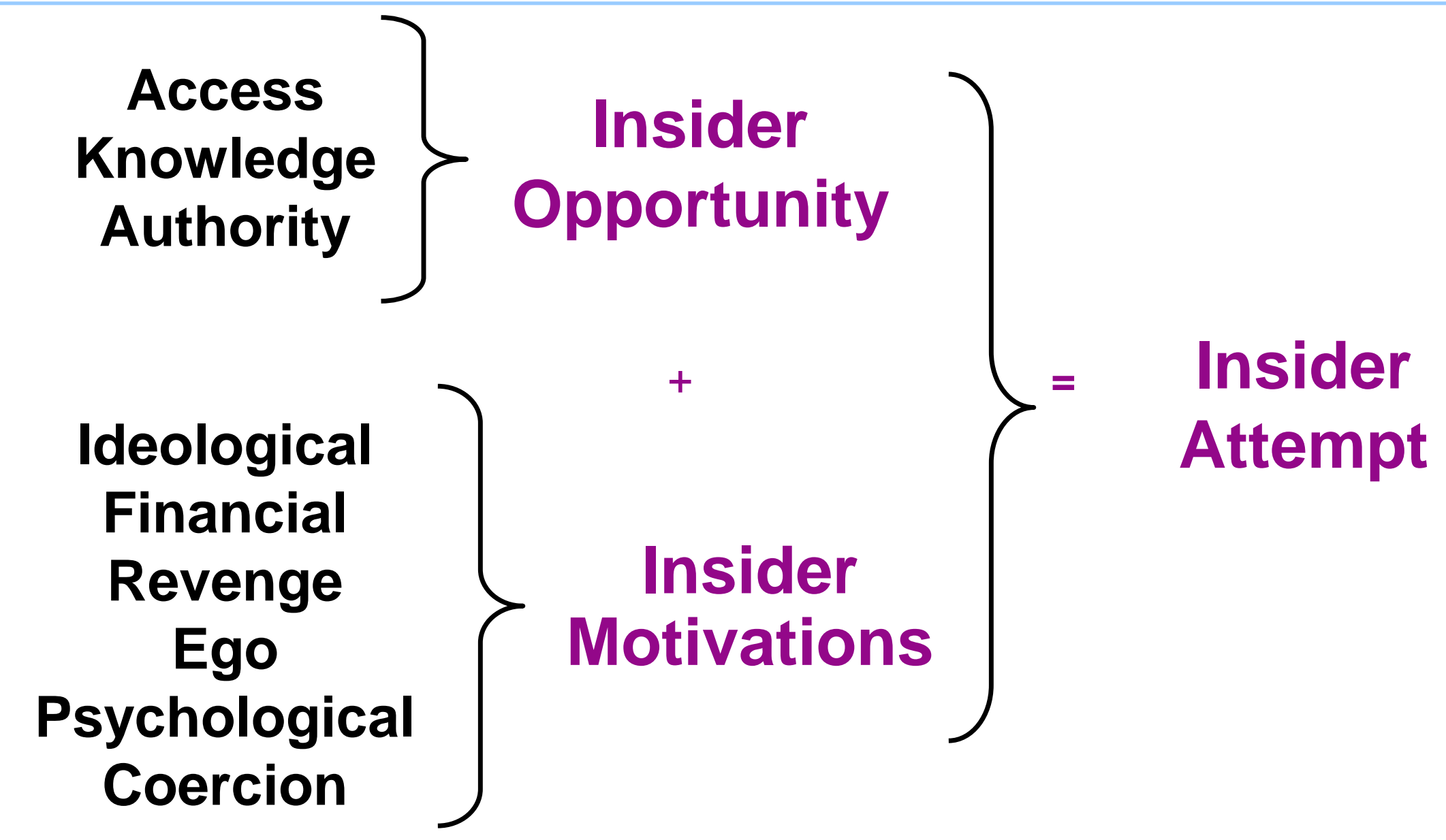




\section{Outsiders}

- Outsider categories

- Terrorists

- Criminals

- Anti-Nuclear Extremists

- Outsider motivations

- Financial

- Ideological 


\section{Outsiders}

(continued)

- Outsider characteristics:

- Equipment

- Weapons

- Methods of attack

- Knowledge of the facility

- Insider Cooperation

- Training

- Funding 


\section{Outsiders}

(continued)

- Outsider Tactics

- Deceit

- Attempt To Defeat A Security System By Using False Authorization And Identification

- Force

- The Overt, Forcible Attempt To Overcome A Security System

- Stealth

- Attempt To Defeat The Detection System And Enter The Facility Covertly 


\section{Insider/Outsider Collusion}

- An insider's knowledge and access combined with outside resources and skills

- Insider can remove delay elements for outsider

- Insider can move target partially along path, to be collected by outsider

- Insider can defeat detection elements (CAS operator ignores alarms, maintenance technician bypasses sensors, etc.)

- Insider can defeat access controls for outsiders (vouches for outsiders, escorts outsiders past security barriers, etc.) 